\title{
OPTICAL RESPONSE STUDY OF THE Al/a-SiC:H SCHOTTKY DIODE FOR DIFFERENT SUBSTRATE TEMPERATURES OF THE r.f. SPUTTERED a-SiC:H THIN FILM
}

\author{
L. MAGAFAS \\ Laboratory of Electrical and Electronic Materials Technology, Department of Electrical and \\ Computer Engineering, Democritous University of Thrace, 67100, Xanthi, Greece
}

(Received 20 November 2001; In final form 16 May 2002)

\begin{abstract}
In the present work, Schottky diodes of $\mathrm{Al} / \mathrm{a}-\mathrm{SiC}: \mathrm{H}$ included in the structure $\mathrm{Al} / \mathrm{a}-\mathrm{SiC}: \mathrm{H} / \mathrm{c}-\mathrm{Si}(\mathrm{n}) / \mathrm{Al}$ were fabricated and their optical response was studied in the wavelength region from $350 \mathrm{~nm}$ up to $1000 \mathrm{~nm}$, for different substrate temperatures, $T_{s}$ (from $30^{\circ} \mathrm{C}$ up to $290^{\circ} \mathrm{C}$ ) of the r.f. sputtered a-SiC:H thin film. The spectral response of these structures exhibits two maximum values of quantum efficiency. The first maximum is presented at wavelength $\lambda \cong 525 \mathrm{~nm}$ and the other at $\lambda=850 \mathrm{~nm}$, which are attributed to the $\mathrm{Al} / \mathrm{a}-\mathrm{SiC}: \mathrm{H}$ Schottky junction and the $\mathrm{a}-\mathrm{SiC}: \mathrm{H} / \mathrm{c}-\mathrm{Si}(\mathrm{n})$ isotype heterojunction, respectively. The position of the first maximum owing to the $\mathrm{Al} / \mathrm{a}-\mathrm{SiC}: \mathrm{H}$ junction as well as the values of quantum efficiency, for the range of wavelengths from $350 \mathrm{~nm}$ up to $700 \mathrm{~nm}$, depends on the substrate temperature, $T_{s}$, of the a-SiC:H thin film. In the case that $T_{s}$ is $120^{\circ} \mathrm{C}$, the spectral response of the $\mathrm{Al} / \mathrm{a}-\mathrm{SiC}: \mathrm{H} / \mathrm{c}-\mathrm{Si}(\mathrm{n}) / \mathrm{Al}$ structure for a reverse bias voltage $V=-2 \mathrm{~V}$ exhibits high values of quantum efficiency (up to $40 \%$ ) with slight variation in the range of wavelength from $475 \mathrm{~nm}$ up to $925 \mathrm{~nm}$, making this structure interesting as a wide band optical sensor device. Finally, the minority carrier (holes) diffusion length of a-SiC:H for $T_{s}=120^{\circ} \mathrm{C}$ was calculated and it was found to be $\cong 2.200 \AA$.
\end{abstract}

Keywords: Schottky diode; Optical sensor; Heterojunction; Diffusion length

\section{INTRODUCTION}

A-SiC:H is a very promising material in many optoelectronic applications such as solar cell [1], color detector [2], light emitting diode and phototransistor [3]. The properties of the above devices can be affected by changing the deposition parameters of the a-SiC: $\mathrm{H}$ thin films, which have crucial effects on the optical and optoelectronic properties of a-SiC:H films. Schottky diodes on a-SiC:H are also very important in their own right and can be used for the understanding and characterization of a-SiC:H and its devices. Despite the importance of a-SiC:H Schottky diodes, there is a dearth of relevant publications $[4,5]$. Consequently, much work is needed in this area in order to understand, and then to improve the optoelectronic properties of Metal/a-SiC:H diodes. 
The present work is a contribution to this particular direction. More specifically, the optical response of the Al/a-SiC:H Schottky junction included in the structure $\mathrm{Al} / \mathrm{a}-\mathrm{SiC}: \mathrm{H} / \mathrm{c}-\mathrm{Si}(\mathrm{n}) / \mathrm{Al}$ is studied, for different substrate temperatures of the r.f. sputtered a-SiC:H thin film. The experimental results show that the values of quantum efficiency as well as the position of the maximum value owing to the $\mathrm{Al} / \mathrm{a}-\mathrm{SiC}: \mathrm{H}$ Schottky junction depend on $T_{s}$. For $T_{s}=120^{\circ} \mathrm{C}$ the overall spectral response of the above structure $(\mathrm{Al} / \mathrm{a}-\mathrm{SiC}: \mathrm{H} / \mathrm{c}-\mathrm{Si}(\mathrm{n}) / \mathrm{Al})$ presents high values of quantum efficiency with slight variation in the range of wavelengths from $475 \mathrm{~nm}$ up to $925 \mathrm{~nm}$, making it interesting as a wide-band optical sensor device.

\section{FABRICATION OF THE Al/a-SiC:H SCHOTTKY DIODE}

A-SiC:H thin films of thickness $5000 \AA$ were deposited by r.f. sputtering on n-type c-Si $(\rho=5-10 \Omega \mathrm{cm})$ substrates, with ohmic contacts (Al) on their back sides. The target used was poly-SiC of constant composition (C 66 wt.\% and Si 34 wt.\%) and $99.8 \%$ purity. The r.f. power was $250 \mathrm{~W}$ and the target to substrate distance was $5.5 \mathrm{~cm}$. The substrate temperature was varied from $30^{\circ} \mathrm{C}$ up to $290^{\circ} \mathrm{C}$ and the sputtering chamber evacuated to a pressure lower than $5 \times 10^{-7}$ Torr, before the introduction of argon. During deposition, the flow rate of argon and hydrogen was $20 \mathrm{sccm}$, and the pressure in the sputtering chamber was $5 \times 10^{-3}$ Torr. After the deposition of a-SiC:H thin films, the samples were placed in a

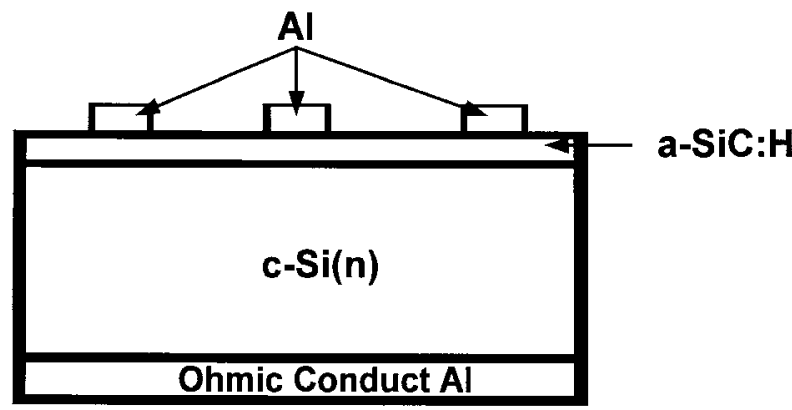

(a)

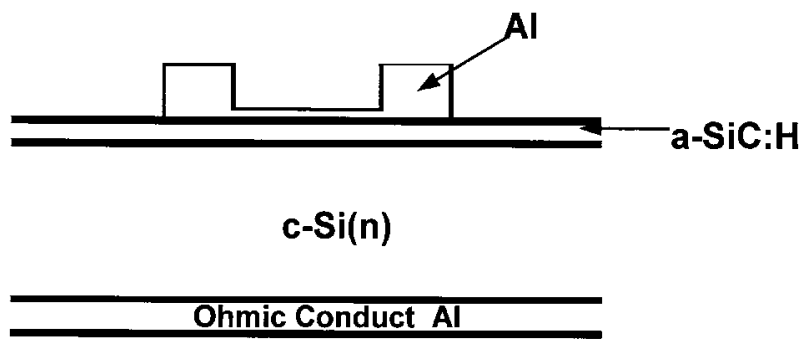

(b)

FIGURE 1 (a) Typical structure of the Al/a-SiC:H Schottky diode. (b) Typical structure used for the measurement of the spectral response of the $\mathrm{Al} / \mathrm{a}-\mathrm{SiC}: \mathrm{H}$ Schottky diode. 
high vacuum evaporator, where aluminum dots ( $1 \mathrm{~mm}$ in diameter) were deposited on the amorphous thin films. Figure 1(a) shows the typical structure of the $\mathrm{Al} / \mathrm{a}-\mathrm{SiC}: \mathrm{H}$ Schottky diode used in the present work.

In order to study the spectral response of the $\mathrm{Al} / \mathrm{a}-\mathrm{SiC}: \mathrm{H}$ Schottky diode, the $\mathrm{Al}$ electrode on the amorphous thin film had the shape shown in Figure 1(b). The metal film in the center of the circular disc was very thin $(<80 \AA)$, in order to be transparent to the incident light, whereas at its circumference it was much thicker (about $5000 \AA$ ) for the electrical connection. To get this form of $\mathrm{Al}$, the as-deposited $\mathrm{Al}$ dots were chemically etched using the photolithography process [6].

\section{EXPERIMENTAL RESULTS}

Previous works [7-9] have shown that the r.f. sputtered a-SiC:H thin film exhibits n-type conductivity and the junction $\mathrm{Al} / \mathrm{a}-\mathrm{SiC}: \mathrm{H}$ behaves as a Schottky one, with very good rectification properties. Also, these works have shown that the optical band gap, $E_{g}$, of the a-SiC:H increases from $2.05 \mathrm{eV}$ up to $2.30 \mathrm{eV}$ with the respective increase of substrate temperature, $T_{s}$, from $30^{\circ} \mathrm{C}$ up to $290^{\circ} \mathrm{C}$, and the photosensitivity presents the optimum value at $T_{s}=120^{\circ} \mathrm{C}$ [8], as well. Figure 2 presents the energy band diagram of the $\mathrm{Al} / \mathrm{a}-\mathrm{SiC}: \mathrm{H} /$ c-Si(n)/Al structure under thermal equilibrium conditions for the case that the a-SiC:H deposited at $120^{\circ} \mathrm{C}$. The above energy band diagram was derived using Anderson's model [10]. The subscripts 1 and 2 refer to a-SiC:H and c-Si(n), respectively, so that $E_{C 1}, E_{C 2}$ are the edges of conduction bands, $E_{V 1}, E_{V 2}$ the edges of valence bands, $\delta_{1}, \delta_{2}$ the distances between the Fermi level and the corresponding conduction band edges, $E_{g 1}, E_{g 2}$ the energy bandgaps, $\Delta E_{C}, \Delta E_{V}$ the discontinuities of the conduction and valence bands, respectively,
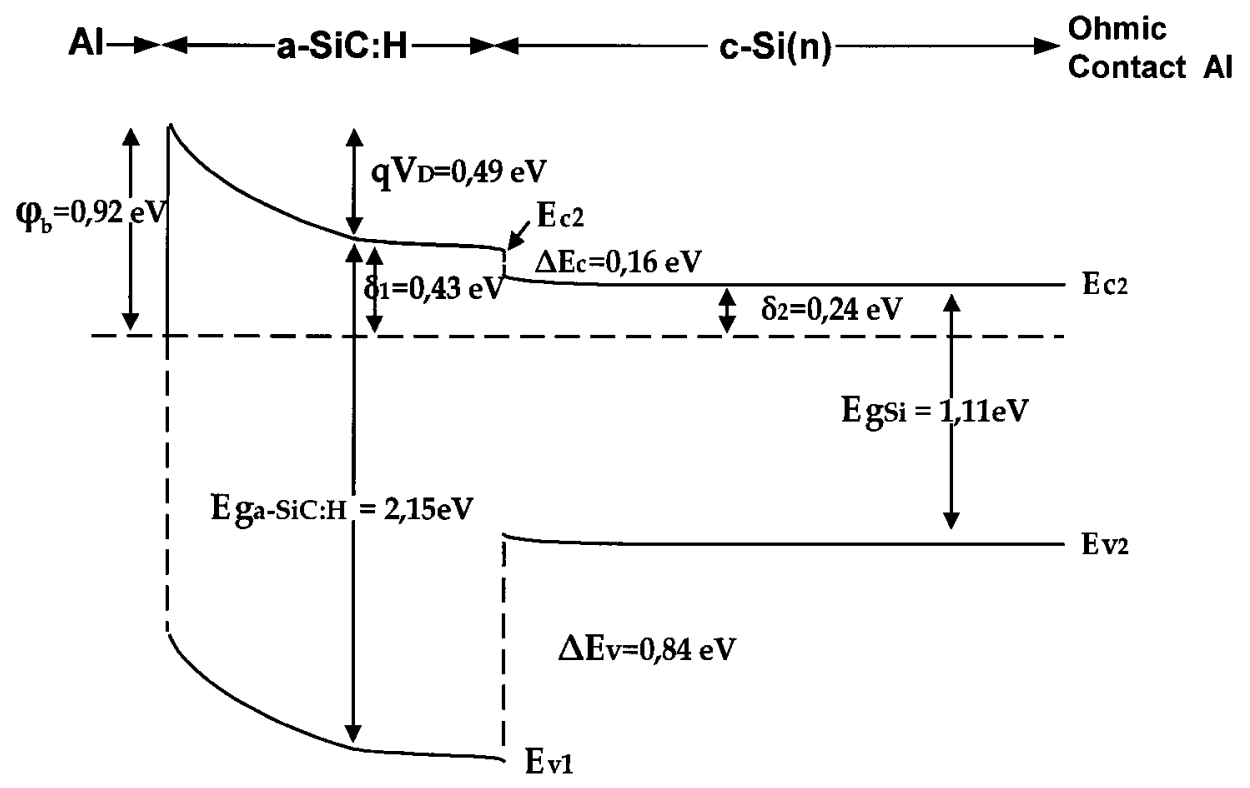

FIGURE 2 Energy band diagram of the $\mathrm{Al} / \mathrm{a}-\mathrm{SiC}: \mathrm{H} / \mathrm{c}-\mathrm{S}(\mathrm{n}) / \mathrm{Al}$ structure under quasi equilibrium. 
$E_{F}$ the Fermi level under thermal equilibrium conditions, $\varphi_{b}$ the potentials barrier of the Schottky junction, $V_{D}, V_{b}$ the total diffusion potential of the $\mathrm{Al} / \mathrm{a}-\mathrm{SiC}: \mathrm{H}$ junction and the a-SiC:H/c-Si(n) junction, respectively, and $V_{b 1}, V_{b 2}$ the partial diffusion potentials of the a-SiC:H/c-Si(n) junction. Take into account that $\varphi_{b}=0.92 \mathrm{eV}[9], V_{D}=0.49 \mathrm{eV}[7,9]$, $\delta_{1}=0.43 \mathrm{eV}$ [7], $\delta_{2}=0.24 \mathrm{eV}$ (extracted from the resistivity value of $\mathrm{Si}$ ), and the well known values of $\mathrm{Al}$ work function $\left(W_{b \mathrm{Al}}=4.28 \mathrm{eV}[6]\right)$ and the electron affinity of c-Si $\left(X_{\mathrm{Si}}=4.01 \mathrm{eV}\right.$ [11]), the value of $V_{b}$ was calculated to be $V_{b}=0.03 \mathrm{eV}$, since $V_{b}=W_{b \mathrm{Al}}-\left(X_{\mathrm{Si}}+\delta_{2}\right)$.

According to the following relations [11]:

$$
\begin{aligned}
& \Delta E_{C}=\delta_{1}-\delta_{2}+V_{b 1}-V_{b 2} \\
& \Delta E_{V}=E_{g 1}-\delta_{1}-\left(E_{g 2}-\delta_{2}\right)+V_{b 1}-V_{b 2}
\end{aligned}
$$

and the reasonable assumption that $V_{b} \cong V_{b 2} \cong 0.03 \mathrm{eV}$, provided that the a-SiC:H/c-Si(n) was determined to be an almost one-sided junction [8], the quantities $\Delta E_{C}$ and $\Delta E_{V}$ were calculated, and found to be $\Delta E_{C}=0.16 \mathrm{eV}$ and $\Delta E_{V}=0.84 \mathrm{eV}$.

Figure 3 shows the experimental results of the spectral response of the $\mathrm{Al} / \mathrm{a}-\mathrm{SiC}: \mathrm{H}$ Schottky junction included in the structure $\mathrm{Al} / \mathrm{a}-\mathrm{SiC}: \mathrm{H} / \mathrm{c}-\mathrm{Si}(\mathrm{n}) / \mathrm{Al}$ for $T_{s}=120^{\circ} \mathrm{C}$ with the respect $E_{g \mathrm{a}-\mathrm{SiC}: \mathrm{H}}=2.15 \mathrm{eV}$, and for two different reverse bias voltages, $V=-0.5 \mathrm{~V}$ and $V=-2 \mathrm{~V}$. As it is clear from this figure for a given reverse bias voltage the measured quantum efficiency, $\eta_{\text {measured }}$, exhibits two maximum values, one at wavelength $\lambda \cong 525 \mathrm{~nm}$ and the other at $\lambda=850 \mathrm{~nm}$. Both of these maximum values can be attributed to the existence of the $\mathrm{Al} / \mathrm{a}-\mathrm{SiC}: \mathrm{H}$ Schottky junction and the a-SiC:H/c-Si(n) isotype

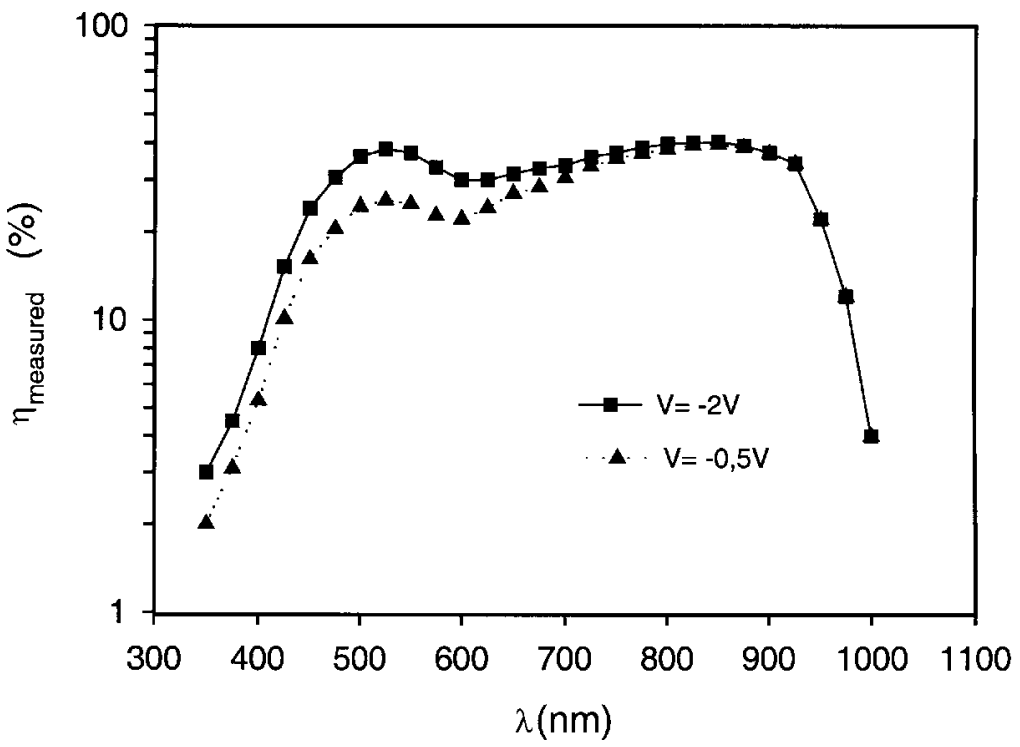

FIGURE 3 Measured quantum efficiency, $\eta_{\text {measured }}$, of the $\mathrm{Al} / \mathrm{a}-\mathrm{SiC}: \mathrm{H}$ Schottky diode included in the $\mathrm{Al} / \mathrm{a}-\mathrm{SiC}: \mathrm{H} / \mathrm{c}-\mathrm{S}(\mathrm{n}) / \mathrm{Al}$ structure as a function of the wavelength, $\lambda$, for a reverse bias voltage $V=-2 \mathrm{~V}(\mathbf{\square})$ and $V=-0.5 \mathrm{~V}(\boldsymbol{\Delta})$, and for substrate temperature $T_{s}=120^{\circ} \mathrm{C}$. 
heterojunction, respectively, since the positions of the two maximum values are slightly smaller to the respected $E_{g}$ of a-SiC:H and c-Si(n), respectively [12]. Also, from the same Figure 3 it is obvious that the first maximum at wavelength $\lambda \cong 525 \mathrm{~nm}$ depends on reverse bias voltage, $V$, in contradiction with the second one. This behavior can be explained by taking into account that the partial applied voltage, $V_{1}$, on the junction $\mathrm{Al} / \mathrm{a}-\mathrm{SiC}: \mathrm{H}$ is much higher than the other one, $V_{2}$, of the junction a-SiC:H/c-Si(n), since $\left(V_{D} / V_{b}>10\right)$ [10], as it was calculated above. In accordance to the above fact, the increase of the reverse bias voltage, from $V=-0.5 \mathrm{~V}$ to $V=-2 \mathrm{~V}$, causes an increase of the depletion region width of the $\mathrm{Al} / \mathrm{a}-\mathrm{SiC}: \mathrm{H}$ junction, leading to higher values of the quantum efficiency of the first maximum only, whereas the values of the second maximum remain almost constant. The possibility that interface or subgab states contribute to the second maximum is not acceptable, since excitations from these states present very low values of the absorption coefficient, $\alpha\left(<10^{3} \mathrm{~cm}^{-3}\right)$, and their total contribution to the quantum efficiency is few percent $[13,14]$. For higher values of reverse bias voltage the quantum efficiency remains almost constant. This means that the volume effect have been saturated or the lack of additional available photogenerated carriers in a-SiC:H. It must be pointed out that the electrical study of the Al/a-SiC:H Schottky diode included in the $\mathrm{Al} / \mathrm{a}-\mathrm{SiC}: \mathrm{H} / \mathrm{c}-\mathrm{Si}(\mathrm{n}) / \mathrm{Al}$ structure [9] did not reveal the existence of another barrier, due to the a-SiC:H/c-Si(n) isotype heterojunction, since this barrier presents lower height in comparison with the Schottky one, as it was found in the present work.

Consequently, illuminating the structure $\mathrm{Al} / \mathrm{a}-\mathrm{SiC}: \mathrm{H} / \mathrm{c}-\mathrm{Si}(\mathrm{n}) / \mathrm{Al}$ from the side of the $\mathrm{Al} / \mathrm{a}-\mathrm{SiC}: \mathrm{H}$ junction, the high energy photons are absorbed near the surface of the a-SiC:H, resulting in the generation of electron-hole pairs which cross the depletion region (electron and holes moving in opposite directions) of the Schottky junction and they are collected. As the wavelength, $\lambda$, increases, the a-SiC:H gradually becomes more and more transparent, and the main region, where absorption of photons takes place, is shifted towards the a-SiC:H/c-S(n) junction, where the photogenerated carriers are collected. The measured quantum efficiency, thus, $\eta_{\text {measured }}$, is the total result of the spectral response of both junctions, $\mathrm{Al} / \mathrm{a}-\mathrm{SiC}: \mathrm{H}, \eta_{1}$, and a-SiC:H/c-S(n), $\eta_{2}$ :

$$
\eta_{\text {measured }}=\eta_{1}+\eta_{2}
$$

Taking into account that the photosensitivity of a-SiC:H and c-Si have different spectra $[12,15]$, as well as the a-SiC:H/c-Si(n) junction was determined to be an almost one-sided junction [8], the measured quantum efficiency in the range of wavelengths from $350 \mathrm{~nm}$ up to $550 \mathrm{~nm}$ is approximately equal to $\eta_{1},\left(\eta_{\text {measured }} \cong \eta_{1}\right)$. On the other hand the total quantum efficiency in the range of wavelengths from $700 \mathrm{~nm}$ up to $1000 \mathrm{~nm}$ is approximately equal to $\eta_{2}\left(\eta_{\text {measured }} \cong \eta_{2}\right)$. The positions of two maximum values of the measured quantum efficiency at $525 \mathrm{~nm}$ and $850 \mathrm{~nm}$ are slightly smaller to the respected $E_{g}$ of a-SiC:H and c-Si(n), respectively, [12]. These are given, qualitatively, in Figure 4.

The experimental results of Figure 3 show that the overall optical response of the $\mathrm{Al} / \mathrm{a}-\mathrm{SiC}: \mathrm{H} / \mathrm{c}-\mathrm{S}(\mathrm{n}) / \mathrm{Al}$ structure for reverse bias voltage $V=-2 \mathrm{~V}$ and $T_{s}=120^{\circ} \mathrm{C}$ exhibits high values of the measured quantum efficiency ( $\cong 40 \%)$ with slight variation in the wavelength region from $475 \mathrm{~nm}$ up to $925 \mathrm{~nm}$. This behavior makes this structure interesting as a wide-band optical sensor device. Also, from the experimental results of the same figure for 


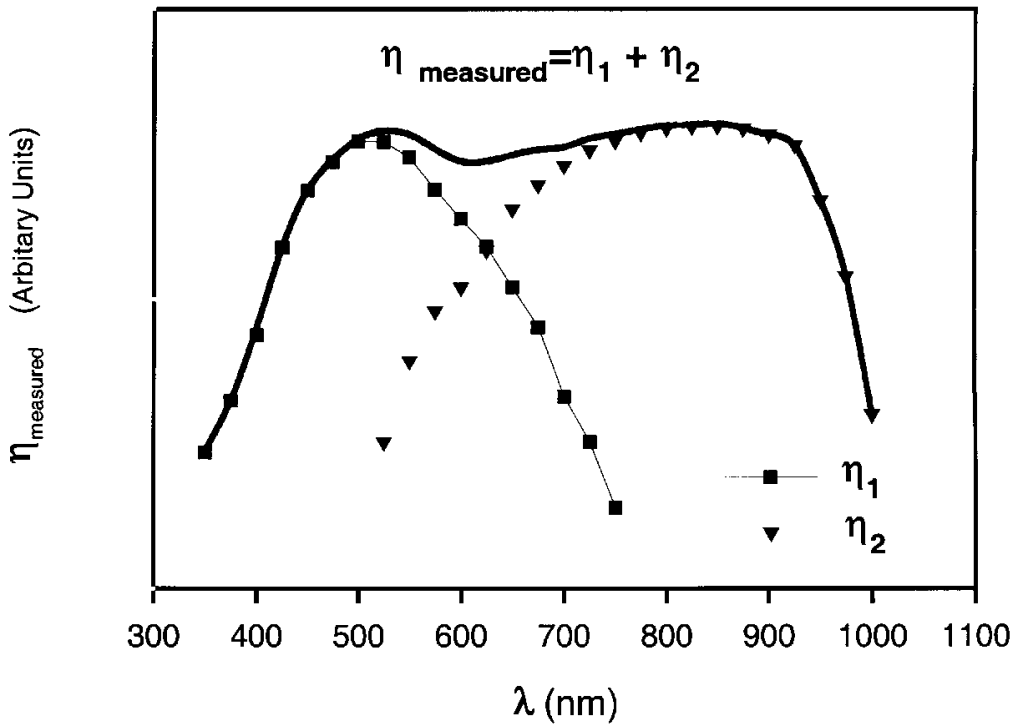

FIGURE 4 Qualitative spectral response of the $\mathrm{Al} / \mathrm{a}-\mathrm{SiC}: \mathrm{H}$ Schottky diode included in the structure $\mathrm{Al} / \mathrm{a}-\mathrm{SiC}: \mathrm{H} / \mathrm{c}-\mathrm{S}(\mathrm{n}) / \mathrm{Al}$. The solid line represents the measured quantum efficiency $\eta_{\text {measured }}$.

the range of $\lambda$ up to $525 \mathrm{~nm}$, where the spectral response is due to the $\mathrm{Al} / \mathrm{a}-\mathrm{SiC}: \mathrm{H}$ junction only, and the expression [12]:

$$
\eta_{\text {measured }}=(1-R)\left(1-\frac{\exp (-\alpha w)}{1+\alpha L_{p}}\right)
$$

where $w$ is the thickness of the depletion region width in a-SiC:H of the $\mathrm{Al} / \mathrm{a}-\mathrm{SiC}: \mathrm{H}$ junction, $R$ is the incident light reflectance of the Al surface, and $\alpha$ is the a-SiC:H absorption coefficient, the value of diffusion length of a-SiC:H holes, $L_{p}$, may be calculated. It was found to be $L_{p} \cong 2.200 \AA$, which is in good agreement with the results from other work [16] for a-SiC:H thin films prepared by glow discharge technique. For the above calculations the values of $R$ and $\alpha$ were taken from other previous works [17, 18], and equal to $52 \%$ and $3.5 \times 10^{4} \mathrm{~cm}^{-1}$, respectively. Also, the thickness of $w$ was determined to be about $2.500 \AA$, by using the estimated value of the effective density of localized states in a-SiC: $\mathrm{H}\left(\cong 5 \times 10^{16} \mathrm{~cm}^{-1}\right)$ [8].

Figure 5 shows the spectral response of the Al/a-SiC:H Schottky diode included in the $\mathrm{Al} / \mathrm{a}-\mathrm{SiC}: \mathrm{H} / \mathrm{c}-\mathrm{Si}(\mathrm{n}) / \mathrm{Al}$ structure for a reverse bias voltage $V=-2 \mathrm{~V}$ and for three different $T_{s}$, i.e. $30^{\circ} \mathrm{C}, 120^{\circ} \mathrm{C}, 290^{\circ} \mathrm{C}$ with $\mathrm{E}_{\mathrm{ga}-\mathrm{SiCi}: \mathrm{H}} 2.05 \mathrm{eV}, 2.15$ and $2.30 \mathrm{eV}$, respectively. As it is clear from this figure the spectral response of these structures for $T_{s}=30^{\circ} \mathrm{C}$ and $T_{s}=290^{\circ} \mathrm{C}$ presents lower values of quantum efficiency in comparison with that of $T_{s}=120^{\circ} \mathrm{C}$, in the range of wavelengths from $350 \mathrm{~nm}$ up to $700 \mathrm{~nm}$. This result can be attributed to the fact that the a-SiC:H thin film deposited at $T_{s}=120^{\circ} \mathrm{C}$ presents the optimum optoelectronic properties [8]. Also, from the same figure it is obvious that the position of the first maximum, owing to the $\mathrm{Al} / \mathrm{a}-\mathrm{SiC}: \mathrm{H}$ Schottky junction, depends on the value of $E_{g \mathrm{a}-\mathrm{SiC}: \mathrm{H}}$. More speci- 


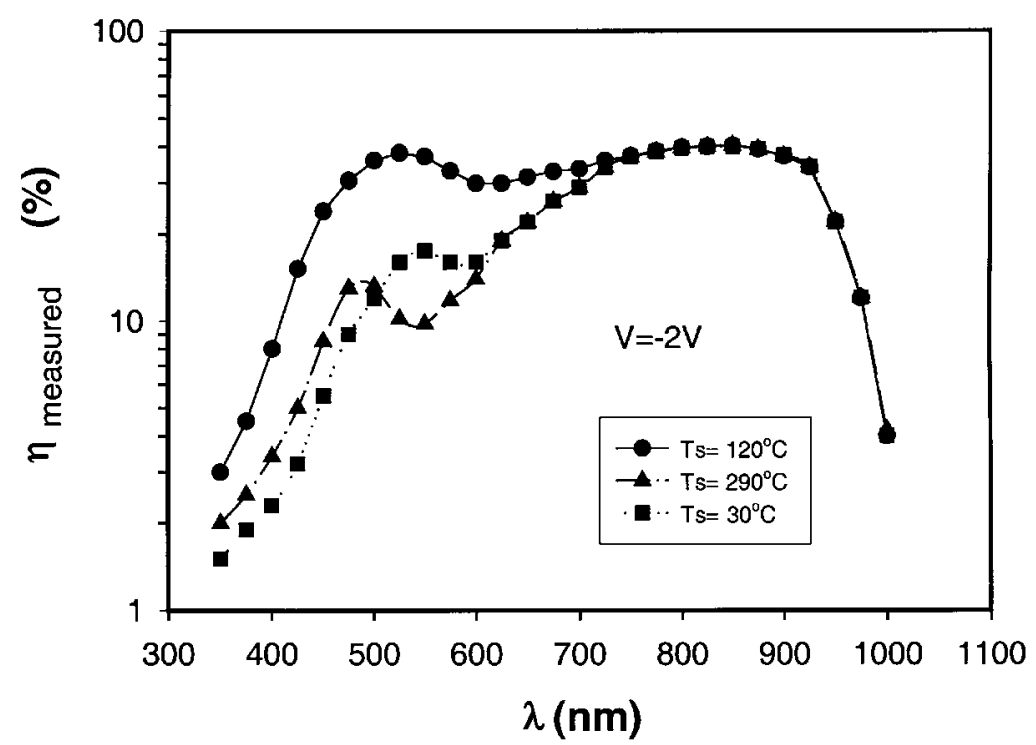

FIGURE 5 Measured quantum efficiency, $\eta_{\text {measured }}$, of the $\mathrm{Al} / \mathrm{a}-\mathrm{SiC}: \mathrm{H}$ Schottky junction included in the $\mathrm{Al} / \mathrm{a}-\mathrm{SiC}: \mathrm{H} / \mathrm{c}-\mathrm{S}(\mathrm{n}) / \mathrm{Al}$ structure, as a function of the wavelength, $\lambda$, for a reverse bias voltage $V=-2 \mathrm{~V}$ and for three different substrate temperatures $T_{s}=30^{\circ} \mathrm{C}(\boldsymbol{\square}), T_{s}=120^{\circ} \mathrm{C}(\bullet)$ and $T_{s}=290^{\circ} \mathrm{C}(\boldsymbol{\Delta})$.

fically, as the $E_{g \text { a-SiC:H }}$ increases the wavelength of the maximum shifts towards the lower wavelength, according to the relation:

$$
\lambda(\mu \mathrm{m})=\left(\frac{1.24}{E_{g}}\right)
$$

This behavior, in conjunction with the fact that the optical band gap of a-SiC:H can be controlled, is very interesting for preparing wide band optical sensor devices, with high photosensitivity in the blue region of the spectra, by using a-SiC:H thin films of different $E_{g}$, in multi-layer heterojunction structures. Additionally, the values of quantum efficiency could be improved by using a suitable anti-reflect coating on the top electrode, since $\mathrm{Al}$ presents high values of reflectance in the visible region of wavelengths.

\section{CONCLUSIONS}

The main conclusions of this work are the following:

1. The spectral response of the $\mathrm{Al} / \mathrm{a}-\mathrm{SiC}: \mathrm{H} / \mathrm{c}-\mathrm{Si}(\mathrm{n}) / \mathrm{Al}$ structure exhibits two maximum values of quantum efficiency. The first maximum is presented at $\lambda \cong 525 \mathrm{~nm}$ and the other at $\lambda=850 \mathrm{~nm}$, which are attributed to the $\mathrm{Al} / \mathrm{a}-\mathrm{SiC}: \mathrm{H}$ Schottky junction and the a-SiC:H/c-Si(n) isotype heterojunction, respectively. The position of the first maximum, owing to the $\mathrm{Al} / \mathrm{a}-\mathrm{SiC}: \mathrm{H}$ Schottky junction, as well as the values of quantum efficiency, for the range of wavelengths from $350 \mathrm{~nm}$ up to $700 \mathrm{~nm}$, were found to depend on the substrate temperature of the r.f. sputtered a-SiC:H thin film. 
2. The overall spectral response of the $\mathrm{Al} / \mathrm{a}-\mathrm{SiC}: \mathrm{H} / \mathrm{c}-\mathrm{Si}(\mathrm{n}) / \mathrm{Al}$ structure for substrate temperature of the a-SiC: $\mathrm{H}$ thin film $T_{s}=120^{\circ} \mathrm{C}$ and a reverse bias voltage $V=-2 \mathrm{~V}$, exhibits high values of quantum efficiency in the range of wavelengths from $475 \mathrm{~nm}$ up to $925 \mathrm{~nm}$, making this structure interesting as a wide-band optical sensor device.

3. The minority carrier (holes) diffusion length of a-SiC:H for $T_{s}=120^{\circ} \mathrm{C}$ was calculated and it was found to be $\cong 2.200 \AA$.

\section{References}

[1] Catalano, A., Newton, J. and Rothwarf, A. (1990). a-SiC:H alloy for multifunction solar cells. IEEE Transactions on Electron Devices, 37(2), 391.

[2] Irrena, F., Lemmi, F. and Palma, F. (1997). Transient behavior of adjustable threshold a-Si:H/a-SiC:H three-color detector. IEEE Transactions on Electron Devices, 47(9), 1410.

[3] Hamakawa, Y., Rahman, M. M., Yang, C. Y.-W. and Harris, G. L. (Eds.) (1989). Amorphous and Crystalline Silicon Carbide and Related Materials. Springer, Berlin, p. 164.

[4] Itoh, K., Matsumoto, H., Kobata, T., Fujishima, A., Nakaomura, O. and Fukui, K. (1983). Determining of leaky Schottky barrier existing in the junction between $\mathrm{SnO}_{2}$ and a highly doped p-type amorphous $\mathrm{SiC}$ by using pulsed laser induced transient photopotential technique. Applied Physics Letters, 51(21), 1686.

[5] Vincenzoni, R., Rossi, M. C., Leo, G. and Galluzzi, F. (1995). Light-modulated carrier injection across the interface between transparent conducting oxide $\left(\mathrm{n}^{+}-\mathrm{SnO}_{2}\right)$ and semi-insulating amorphous silicon-carbide. Journal of Non-Crystalline Solids, 187, 489.

[6] Borstein, L. (1984). Numerical Data and Functional Relationships in Science and Technology. Springer-Verlag, Berlin-Heidelberg, p. 235.

[7] Magafas, L., Georgoulas, N., Girginoudi, D. and Thanailakis, A. (1991). The dependence of electrical and optical properties of R.F sputtered amorphous silicon carbon alloy thin films on substrate temperature and hydrogen flow rate. Physical Status Solidi (a), 124, 143.

[8] Magafas, L. (1992). Deposition, properties, and applications of amorphous semiconductors. PhD thesis, Democritous University of Thrace, Xanthi.

[9] Magafas, L., Georgoulas, N. and Thanailakis, A. (1997). The influence of metal work function on electrical properties of metal/a-SiC:H Schottky diodes. Microelectronics Journal, $28,1$.

[10] Anderson, R. (1962). Experiments on Ge-GaAs heterojunctions. Solid-State Electron, 45(9), 341.

[11] Sharma, B. L. and Purohit, R. K. (1974). Semiconductor Heterojunctions, Int. Series of Monographs in the Science of Solid State, 5, Chap. 2. Pergamon, New York, p. 25.

[12] Sze, S. M. (1985). Physics of Semiconductor Devices, 2nd ed. John Wiley and Sons Inc., New York, p. 751.

[13] Aeschbacher, H. N. (Ed.) (1995). Hydrogenated amorphous silicon. Solid State Phenomena, 809, 44-46, Part 2.

[14] Kosyachenco, L. A., Sklyarchuk, V. M. and Sklyarchuk, Y. F. (1998). Electrical and photoelectric properties of Au-SiC Schottky barrier diodes. Solid Syate Electronics, $42,145$.

[15] Hamakawa, Y. (Ed.) (1984). Amorphous Semiconductor Technology and Devices. North Holland, Amsterdam, p. 180.

[16] Wang, F. and Schwarz, R. (1993). Characterization properties of a-SiC:H films. Journal of Non-Crystalline Solids, 164-166, 1039.

[17] (1972). Handbook of American Institute of Physics, pp. 6-159.

[18] Magafas, L., Georgoulas, N., Girginoudi, D. and Thanailakis, A. (1992). Structural and optical properties of a-SiC:H thin films. Journal of Non-Crystalline Solids 139, 143. 

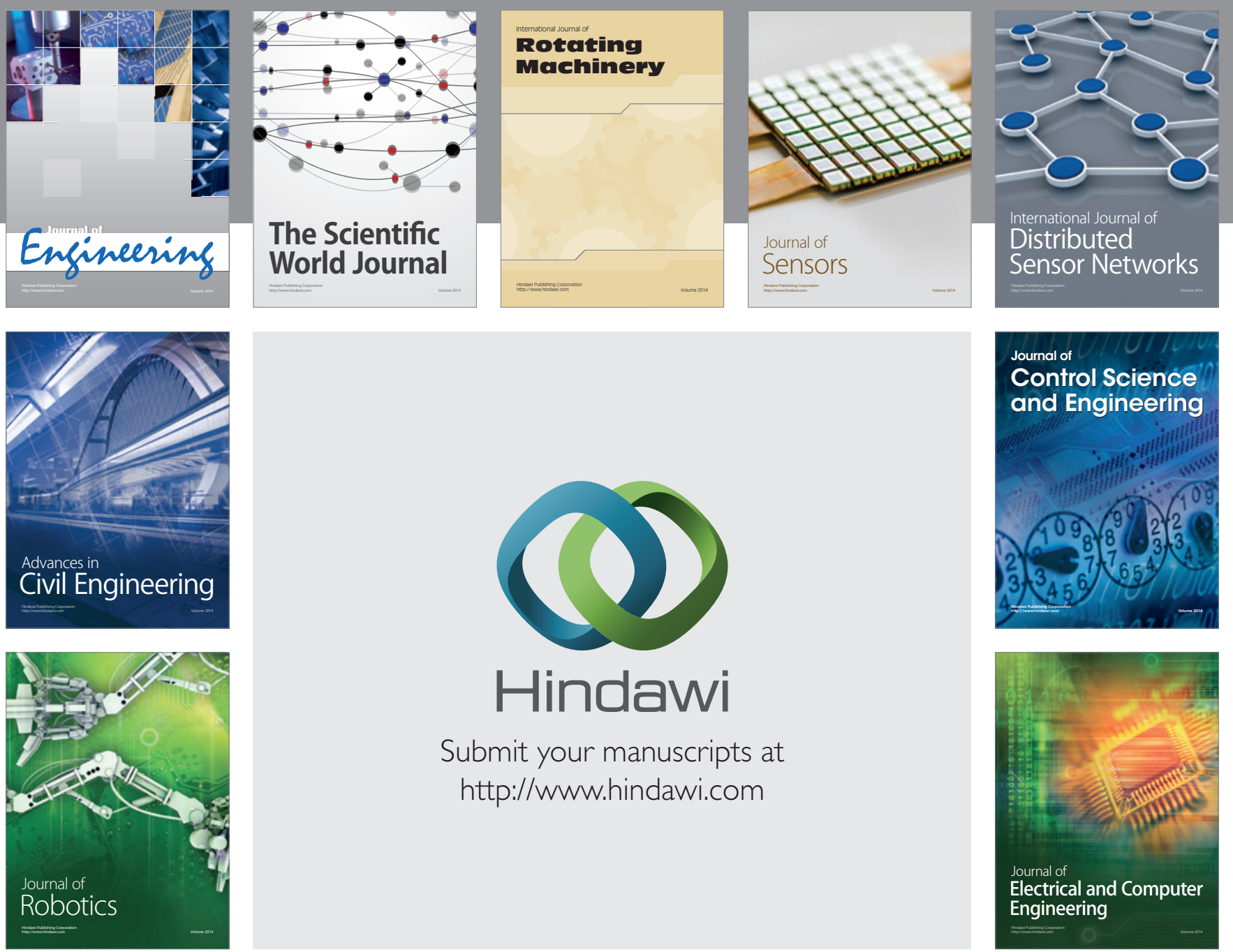

Submit your manuscripts at

http://www.hindawi.com
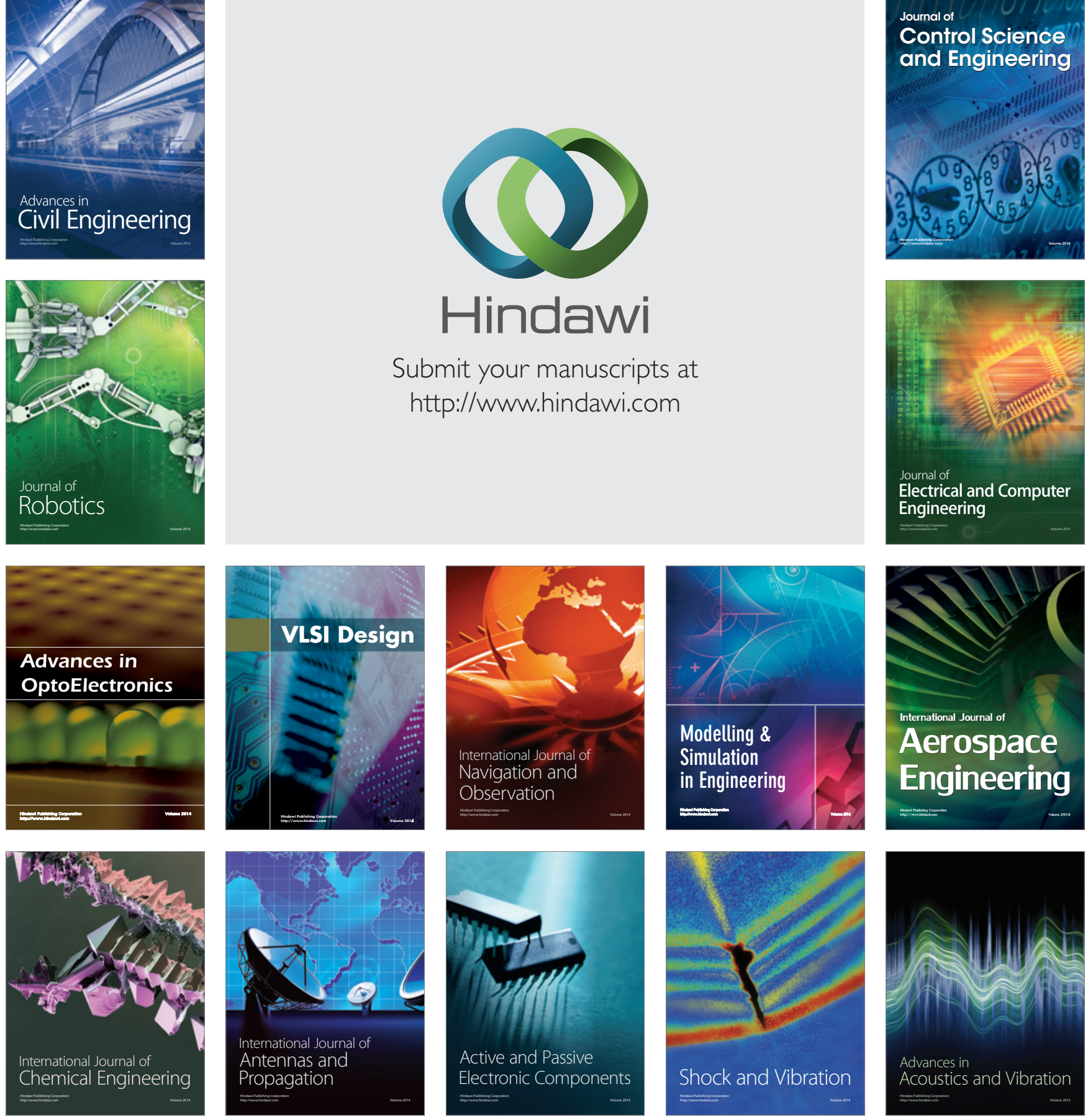